\title{
Can robotic assisted laparoscopic prostatectomy be recommended to obese patients?
}

\author{
Laura E. Crocitto · Martina Ly $\cdot$ Roger Satterthwaite • \\ Timothy Wilson $\cdot$ Rebecca A. Nelson
}

Received: 2 October 2007/Accepted: 5 December 2007/Published online: 4 January 2008

(C) Springer London 2007

\begin{abstract}
Experienced robotic surgeons report lower estimated blood loss (EBL) and transfusion rates with similar clinical outcomes for robotic assisted laparoscopic radical prostatectomy (RALP) compared to open radical retropubic prostatectomy (RRP). We reviewed our experience with RALP to investigate how to counsel overweight and obese patients being considered for RALP regarding risk of major perioperative complications, oncological outcomes, and short-term recovery. We reviewed the data on 1,513 patients who underwent RALP by one of four experienced robotic surgeons between June 2003 and November 2006. These patients were categorized as normal, overweight, obese, and severely obese based on body mass index (BMI). Of these patients, 361 (23.9\%) had a BMI under 25, $794(52.5 \%)$ had a BMI between 25 and 30 (overweight), 290 (19.2\%) had a BMI between 30 and 35 (obese), and 68 (4.5\%) had a BMI over 35 (severely obese). Records were examined and analyzed with respect to BMI for major intra- and perioperative complications, operative time, margin status, EBL, transfusion rates, and length of hospital stay. Increasing BMI was associated with longer operative time, with mean operative times of 2.7 , $2.8,3.1$, and $3.3 \mathrm{~h}$ for normal, overweight, obese and
\end{abstract}

L. E. Crocitto - M. Ly · R. Satterthwaite · T. Wilson

Department of Urology, City of Hope, Duarte, CA 91010, USA

R. A. Nelson

Department of Biostatistics, City of Hope, Duarte, CA 91010, USA

L. E. Crocitto ( $\square)$

1500 East Duarte Road, Duarte, CA 91010, USA

e-mail: 1crocitto@coh.org severely obese patients, respectively $(P<0.0001)$. Higher blood loss, though not clinically significant, was also associated with increased BMI, with obese and severely obese patients losing a median of $250 \mathrm{~mL}$ of blood compared to $200 \mathrm{~mL}$ in overweight and non-overweight patients $(P<0.0001)$. Transfusion rates, intra- and perioperative complications, margin status, and length of stay were not found to be associated with BMI group. Robotic assisted laparoscopic radical prostatectomy in experienced hands can be safely recommended to eligible patients regardless of BMI status.

Keywords Robotic prostatectomy - Body mass index . Complications · Prostate cancer

\section{Introduction}

The increase in prostate specific antigen (PSA) testing in the United States since the early 1990s has resulted in an increase in prostate cancer incidence along with an associated downward stage migration [1]. In turn, the number of radical prostatectomies performed each year has also risen and promises to continue to rise, based on projected increases in the population size, the life expectancy (now 78 years in the USA) and fraction of the population over the age of 65 [2]. Concurrently, the estimated prevalence of overweight (BMI 25.0-29.9 $\mathrm{kg} / \mathrm{m}^{2}$ ) and obese (BMI $\geq 30 \mathrm{~kg} / \mathrm{m}^{2}$ ) adults aged $20-74$ years in the US has also increased steadily over the last 25 years from 15 to $31 \%$ today [3]. Since 2000, when the da Vinci surgical system was first introduced to the US, the absolute number and percentage of patients with prostate cancer treated with robotic-assisted laparoscopic radical prostatectomy (RALP) has steadily increased. It is now estimated that 
approximately $63 \%$ of all radical prostatectomies will be performed robotically in 2007 [4].

Over the past 5 years, reports on minimally invasive techniques for prostate cancer have shown that patients treated by either laparoscopic radical prostatectomy (LRP) or RALP consistently have lower blood loss and transfusion rates. Perioperative morbidity, hospital stay, complications, and recovery are at least equal to if not better than reports of those treated with open radical retropubic prostatectomy (RRP) [5, 6]. Studies looking at the impact of obesity on RALP are limited and have shown mixed results. Ahlering et al. [7] reported on a series of 100 RALPs. Obese patients with a BMI greater than 30 had higher blood loss, complication rate, and operative times compared to patients with a BMI less than 30. However, other investigations have shown no differences in complication rates, margin status, hospital stay, blood loss, and recurrence in comparison to the normal weight cohort [810]. All of these reports are limited by the sample size.

We evaluated the surgical outcomes in obese versus normal weight subjects in one of the largest single-institution robotic prostatectomy cohorts. Using our institutional review board (IRB)-approved database of preand postsurgery information collected on 1,513 RALP patients, we report on the perioperative and clinical outcomes in our patients with regard to BMI status.

\section{Materials and methods}

In December 2000, the Department of Urology established a prostate cancer database. The database collection system consists of Verity Teleform scannable forms, image data capture, and an MS SQL Server database. All patients with prostate cancer who presented to $\mathrm{COH}$ on or after January 1, 1995 and who received at least part of their treatment at $\mathrm{COH}$ were evaluated for inclusion in this IRB-approved database. Patient consent was obtained prior to enrollment into the database. Data were then collected prospectively from the time of consent on operative parameters and outcomes; 1,513 consecutive patients enrolled in the database underwent RALP by four surgeons at our institution between June 2003 and November 2006. Any patient otherwise considered a candidate for RRP was offered RALP. Body habitus was not considered a contraindication. From June 2003 to November 2006, $96.8 \%$ of radical prostatectomies at our institution were performed robotically. All eligible patients were included in the analysis without regard to learning curve or surgeon experience. Subjects were divided into four categories according to preoperative BMI $\left(\mathrm{kg} / \mathrm{m}^{2}\right)$ : normal (BMI $\left.<25\right)$, overweight (BMI 2529.9), mildly obese (BMI 30-34.9), and severely obese
$($ BMI > 35). Height and weights were obtained from direct measurements. Factors analyzed for this report include: age, race, BMI, PSA, pretreatment Gleason score, clinical stage, operative time, nerve-sparing status, specimen weight, pathologic stage and grade, margin status, intraoperative and postoperative complications (within 30 days of surgery), catheterization time, physicianreported time to continence (use of $1 \mathrm{pad} / \mathrm{day}$ for security purposes only), and length of hospitalization.

Surgical technique and early postoperative care

All prostatectomies were performed transperitoneally with $\mathrm{COH}$ modifications to the Montsouris technique [11]. A four-arm robot with two assistant ports for a total of six ports was used for RALP. The fourth arm was placed through a port that was medial to the left anterior superior iliac spine. The bladder was mobilized completely by bilaterally incising the peritoneum lateral to the medial umbilical ligaments. The medial umbilical ligaments and urachus were divided as cephalad as possible. The endopelvic fascia was opened to gain access to the prostatic apex and expose the deep dorsal venous complex. The dorsal vein complex was divided and controlled with an endovascular stapler (Ethicon $45 \mathrm{~mm}$ ). For the urethrovesical anastomosis, one to three posterior anastomotic sutures were interrupted (depending on surgeon preference) followed by two running sutures from the 5 and 7 o'clock to 12 o'clock positions. Catheters were removed on postoperative day (POD) 4 to 7 according to the practice pattern of the treating surgeon. No procedures were aborted and no patients underwent open conversion.

\section{Histopathological analysis}

Surgical specimens were fixed intact in $10 \%$ neutrally buffered formalin. The outer surface was inked to delineate the surgical margins (black) and the left (green) and right (blue) orientation. Prostate and seminal vesicles were sectioned transversely at approximately $5 \mathrm{~mm}$ intervals, depending on the size of the specimen. The pathologist identified the location and extent of cancer. The presence and location of extracapsular extension, seminal vesicle invasion, lymph node metastasis, and histological grade were recorded. A positive surgical margin was defined as tumor cells reaching the inked surface. Extracapsular extension was defined as tumor cells reaching the periprostatic adipose tissue with or without a positive surgical margin. 
Table 1 Baseline characteristics of prostate cancer patients receiving RAP by BMI status

\begin{tabular}{|c|c|c|c|c|c|}
\hline & $\begin{array}{l}\text { Normal } \\
\text { BMI }<25 \\
n=361\end{array}$ & $\begin{array}{l}\text { Overweight } \\
\text { BMI 25-29.9 } \\
n=794\end{array}$ & $\begin{array}{l}\text { Mildly obese } \\
\text { BMI 30-34.9 } \\
n=290\end{array}$ & $\begin{array}{l}\text { Severely obese } \\
\text { BMI } 35+ \\
n=68\end{array}$ & $P$ value \\
\hline Age at surgery (year), mean (std) & $64.6 \pm 8.0$ & $62.6 \pm 7.4$ & $62.6 \pm 7.3$ & $61.1 \pm 7.3$ & $<0.0001$ \\
\hline \multicolumn{6}{|l|}{ Race, $N(\%)$} \\
\hline White & $307(85.0)$ & $728(91.7)$ & $265(91.4)$ & $60(88.2)$ & \multirow[t]{4}{*}{0.0002} \\
\hline Asian & $39(10.8)$ & $37(4.7)$ & $13(4.5)$ & $2(2.9)$ & \\
\hline Black & $10(2.8)$ & $24(3.0)$ & $12(4.1)$ & $6(8.8)$ & \\
\hline Other & $5(1.4)$ & $5(0.6)$ & $0(0.0)$ & $0(0.0)$ & \\
\hline PSA (ng/mL), median (std) & $5.3 \pm 11.0$ & $5.4 \pm 5.4$ & $5.6 \pm 6.5$ & $5.5 \pm 7.9$ & 0.12 \\
\hline \multicolumn{6}{|l|}{ PSA group, $N(\%)$} \\
\hline $0-3.9$ & $72(20.1)$ & $158(20.1)$ & $41(14.3)$ & $13(19.4)$ & \multirow[t]{3}{*}{0.13} \\
\hline $4-10$ & $236(65.9)$ & $541(68.9)$ & $198(69.2)$ & $45(67.2)$ & \\
\hline$>10$ & $50(14.0)$ & $86(11.0)$ & $47(16.4)$ & $9(13.4)$ & \\
\hline \multicolumn{6}{|l|}{ Clinical stage, $N(\%)$} \\
\hline T1abc & $300(83.1)$ & $666(84.2)$ & $249(85.9)$ & $59(86.8)$ & \multirow[t]{2}{*}{0.74} \\
\hline $\mathrm{T} 12 / 3$ & $61(16.9)$ & $125(15.8)$ & $41(14.1)$ & $9(13.2)$ & \\
\hline \multicolumn{6}{|l|}{ Gleason score, $N(\%)$} \\
\hline $2-4$ & $1(0.3)$ & $1(0.1)$ & $0(0.0)$ & $0(0.0)$ & \multirow[t]{4}{*}{0.004} \\
\hline $5-6$ & $224(62.1)$ & $514(65.2)$ & $180(62.5)$ & $34(50.0)$ & \\
\hline 7 & $112(31.0)$ & $228(28.9)$ & $90(31.3)$ & $20(29.4)$ & \\
\hline $8-10$ & $24(6.7)$ & $46(5.8)$ & $18(6.3)$ & $14(20.6)$ & \\
\hline Gleason score, mean (std) & $6.4 \pm 0.7$ & $6.4 \pm 0.7$ & $6.4 \pm 0.7$ & $6.8 \pm 0.9$ & 0.002 \\
\hline \multicolumn{6}{|l|}{ Risk group, $N(\%)$} \\
\hline Low risk & $195(54.5)$ & $463(59.4)$ & $154(54.0)$ & $31(46.3)$ & \multirow[t]{3}{*}{0.002} \\
\hline Intermediate risk & $125(34.9)$ & $250(32.1)$ & $107(37.5)$ & $20(29.9)$ & \\
\hline High risk & 38 (10.6) & $66(8.5)$ & $24(8.4)$ & $16(23.9)$ & \\
\hline \multicolumn{6}{|l|}{ Surgeon, $N(\%)$} \\
\hline A & $158(43.8)$ & $349(44.0)$ & $106(36.6)$ & $27(39.7)$ & \multirow[t]{4}{*}{0.30} \\
\hline $\mathrm{B}$ & $142(39.3)$ & $305(38.4)$ & $117(40.3)$ & $27(39.7)$ & \\
\hline $\mathrm{C}$ & $46(12.7)$ & $94(11.8)$ & $41(14.1)$ & $9(13.2)$ & \\
\hline $\mathrm{D}$ & $15(4.2)$ & $46(5.8)$ & $26(9.0)$ & $5(7.4)$ & \\
\hline
\end{tabular}

\section{Statistical analysis}

Data analysis was performed using Statistical Analysis System software (SAS Institute, Cary, NC, USA). Data were summarized using descriptive statistics, including means for normally distributed continuous data, medians for nonnormally distributed continuous data, and proportions for categorical data. Univariate analyses determining group differences were performed using Pearson's $X^{2}$ test statistic for categorical data, Student's $t$-test statistic for normally distributed continuous data, and the KruskalWallis test for nonnormally distributed continuous data. Log-rank tests were used to assess time-dependent differences across groups (e.g., days to catheter removal and months to continence). Missing data were excluded from the analyses.

\section{Results}

Demographic and clinical data

Table 1 presents the initial clinical and demographic data for all four groups of patients: normal, overweight, mildly obese, and severely obese. The severely obese group was noted to be significantly younger at presentation $(P=0.0001)$ and with a higher mean Gleason score $(P=0.002)$. There was no significant difference in clinical stage and preoperative PSA but severely obese patients were more likely to be categorized in the D'Amico [12] high-risk category preoperatively $(P=0.002)$. In addition, there were a higher percentage of African Americans in the obese and severely obese groups whereas there was a higher percentage of Asians in the normal BMI group $(P=0.0002)$. 
Table 2 Operative and oncological characteristics of prostate cancer patients receiving RAP by BMI status

\begin{tabular}{|c|c|c|c|c|c|}
\hline & $\begin{array}{l}\text { Normal } \\
\text { BMI }<25 \\
n=361\end{array}$ & $\begin{array}{l}\text { Overweight } \\
\text { BMI 25-29.9 } \\
n=794\end{array}$ & $\begin{array}{l}\text { Mildly obese } \\
\text { BMI 30-34.9 } \\
n=290\end{array}$ & $\begin{array}{l}\text { Severely obese } \\
\text { BMI } 35+ \\
n=68\end{array}$ & $P$ value \\
\hline Operation time (hours), mean (std) & $2.7 \pm 0.7$ & $2.8 \pm 0.7$ & $3.1 \pm 0.9$ & $3.3 \pm 1.0$ & $<0.0001$ \\
\hline \multicolumn{6}{|l|}{ Nerve sparing, $N(\%)$} \\
\hline Nerve sparing, bilateral & $317(88.1)$ & $700(88.4)$ & $244(84.4)$ & $51(75.0)$ & \multirow[t]{3}{*}{0.02} \\
\hline Nerve sparing, unilateral & $19(5.3)$ & $46(5.8)$ & $17(5.9)$ & $6(8.8)$ & \\
\hline Non-nerve-sparing & $24(6.7)$ & $46(5.8)$ & $28(9.7)$ & $11(16.2)$ & \\
\hline Estimated blood loss (mL), median (std) & $200 \pm 172$ & $200 \pm 180$ & $250 \pm 235$ & $250 \pm 202$ & $<0.0001$ \\
\hline \multicolumn{6}{|l|}{ Blood transfusion, $N(\%)$} \\
\hline No & $344(97.7)$ & $767(98.3)$ & $280(99.3)$ & $66(98.5)$ & \multirow[t]{2}{*}{0.49} \\
\hline Yes & $8(2.3)$ & $13(1.7)$ & $2(0.7)$ & $1(1.5)$ & \\
\hline \multicolumn{6}{|l|}{ Major complications (intraop.), $N(\%)$} \\
\hline No & $357(98.9)$ & $788(99.2)$ & $288(99.3)$ & $68(100.0)$ & \multirow[t]{2}{*}{0.79} \\
\hline Yes & $4(1.1)$ & $6(0.8)$ & $2(0.7)$ & $0(0.0)$ & \\
\hline \multicolumn{6}{|l|}{ Major complications (periop.), $N(\%)$} \\
\hline No & $293(84.7)$ & $641(84.1)$ & $228(81.1)$ & $55(82.1)$ & \multirow[t]{2}{*}{0.62} \\
\hline Yes & $53(15.3)$ & $121(15.9)$ & $53(18.9)$ & $12(17.9)$ & \\
\hline Specimen wt (grams), mean (std) & $52.2 \pm 21.8$ & $54.6 \pm 21.4$ & $57.0 \pm 25.8$ & $51.7 \pm 19.7$ & 0.04 \\
\hline \multicolumn{6}{|l|}{ Path T stage, $N(\%)$} \\
\hline T0 & $2(0.6)$ & $3(0.4)$ & $1(0.4)$ & $0(0.0)$ & \multirow[t]{3}{*}{0.58} \\
\hline $\mathrm{pT} 1 / 2$ & $307(84.0)$ & $691(87.1)$ & $242(83.5)$ & $55(80.9)$ & \\
\hline pT3 & $52(14.4)$ & $99(12.5)$ & $47(16.2)$ & $13(19.1)$ & \\
\hline \multicolumn{6}{|l|}{ Gleason score, $N(\%)$} \\
\hline $5-6$ & $152(42.8)$ & $373(47.8)$ & $118(41.7)$ & $22(36.1)$ & \multirow[t]{3}{*}{0.08} \\
\hline 7 & $189(53.2)$ & $368(47.3)$ & $145(51.2)$ & $33(54.1)$ & \\
\hline $8-10$ & $14(3.9)$ & $38(4.9)$ & $20(7.1)$ & $6(9.8)$ & \\
\hline Gleason score, mean (std) & $6.6 \pm 0.6$ & $6.6 \pm 0.7$ & $6.7 \pm 0.7$ & $6.8 \pm 0.8$ & 0.06 \\
\hline \multicolumn{6}{|l|}{ Path node status, $N(\%)$} \\
\hline Negative & $210(98.1)$ & $458(98.9)$ & $166(98.8)$ & $42(97.7)$ & \multirow[t]{2}{*}{0.79} \\
\hline Positive & $4(1.9)$ & $5(1.1)$ & $2(1.2)$ & $1(2.3)$ & \\
\hline \multicolumn{6}{|l|}{ SV invasion, $N(\%)$} \\
\hline Negative & $339(93.9)$ & $748(94.4)$ & $265(92.3)$ & $62(91.2)$ & \multirow[t]{2}{*}{0.49} \\
\hline Positive & $22(6.1)$ & $44(5.6)$ & $22(7.7)$ & $6(8.8)$ & \\
\hline \multicolumn{6}{|l|}{ Surgical margins, $N(\%)$} \\
\hline Negative & $279(77.3)$ & $595(75.2)$ & $215(74.4)$ & $46(68.7)$ & \multirow[t]{2}{*}{0.4} \\
\hline Positive & $82(22.7)$ & $196(24.8)$ & $74(25.6)$ & $21(31.3)$ & \\
\hline \multicolumn{6}{|l|}{ Extracapsular extension, $N(\%)$} \\
\hline Negative & $320(88.6)$ & $714(90.2)$ & $254(87.9)$ & $56(82.4)$ & \multirow[t]{2}{*}{0.21} \\
\hline Positive & $41(11.4)$ & $78(9.9)$ & $35(12.1)$ & $12(17.7)$ & \\
\hline
\end{tabular}

Surgical and pathologic outcomes

Outcomes according to BMI are summarized in Table 2. In comparison to the normal and overweight groups, the obese and mildly obese patients had significantly longer operative times $(P<0.0001)$, greater intraoperative blood loss $(P<0.0001)$, and were more likely to undergo a non-nervesparing procedure $(P=0.02)$. There were no significant differences in intraoperative or perioperative complications, transfusion rates, median time to continence or hospital stay. In addition, there was no significant difference in pathologic stage, grade, or margin status (Table 3).

\section{Discussion}

As RALP becomes more widely available, robotic surgeons continue to explore the challenges and capabilities of 
Table 3 Postoperative characteristics of prostate cancer patients receiving RAP by BMI status

\begin{tabular}{lcccc}
\hline & $\begin{array}{l}\text { Normal } \\
\text { BMI }<25 \\
n=361\end{array}$ & $\begin{array}{l}\text { Overweight } \\
\text { BMI 25-29.9 } \\
n=794\end{array}$ & $\begin{array}{l}\text { Mildly Obese } \\
\text { BMI 30-34.9 } \\
n=290\end{array}$ & $\begin{array}{l}\text { Severely Obese } \\
\text { BMI 35+ } \\
n=68\end{array}$ \\
\hline Hospital stay, $N(\%)$ & & & & \\
& & & \\
$0-2$ & $306(84.8)$ & $691(87.1)$ & $243(83.8)$ & $55(80.9)$ \\
$3+$ & $55(15.2)$ & $103(12.9)$ & $47(16.2)$ & $13(19.1)$ \\
Hospital stay (days), median (std) & $2 \pm 1.7$ & $2 \pm 1.5$ & $2 \pm 1.6$ & $2 \pm 1.1$ \\
Days to catheter removal, median (std error) & $7 \pm 7.9$ & $7 \pm 4.0$ & $7 \pm 4.7$ & $7 \pm 9.4$ \\
Months to continence, median (std error) & $3.7 \pm 0.5$ & $2.9 \pm 0.3$ & $4.0 \pm 0.4$ & $4.2 \pm 0.6$ \\
\hline
\end{tabular}

* Log-rank $P$ value

the da Vinci system, including those pertaining to obesity. Some studies have found that obesity is associated with increased technical difficulty and higher complication rates in open [13] and laparoscopic prostate surgery [14, 15]. During open radical prostatectomy, abdominal fat can limit surgical exposure and access to the prostate and may increase the likelihood of greater EBL and intraoperative complications. Although surgical visualization of the radical prostatectomy field is magnified in laparoscopic surgery, instrument mobility within the ports is limited in obese patients [8]. Indeed, RALP in obese patients has been reported to be associated with longer operative times, higher estimated blood loss and complications, and delayed recovery of continence [7-9].

Oncologically, increasing obesity defined by BMI has been associated with an increased risk of more aggressive prostate cancer and an increase in prostate cancer mortality [16-18]. This may be related to differences in several hormonal and metabolic factors seen in obese men versus normal weight men. In our cohort we noticed that mildly and severely obese patients present at an earlier age with more aggressive disease as defined by the D'Amico risk stratification. This may explain why our obese patients were more likely to undergo a non-nerve-sparing procedure.

Compared to non-obese men, higher biochemical failure rates have been reported among obese men [16]. These higher recurrence rates may not only be influenced by a more aggressive disease but also by the technical surgical difficulties prevalent in obese patients. Most surgical series found that obese men undergoing radical prostatectomy, either open or perineal, had a higher positive margin rate [19-21]; however, there is limited literature evaluating this risk in minimally invasive series. In our RALP series, obese men did not differ significantly in margin status. This may be related to the specific surgical technique or to the addition of the da Vinci system when compared to open or laparoscopic series.
There was an increasing trend in mean operative time as BMI increased, which is consistent with other previous LRP and RALP reports $[8,10,14]$. Though we did not time each step in the surgical procedure, other RALP series in obese men have reported difficulties in urethral dissection, urethral anastomosis, port placement [8], and instrument positioning [9]. Obese men tend to have thicker abdominal walls, which require longer surgical instruments and adjustment of the robotic port sites [9]. In addition to a thicker abdominal wall, more intraperitoneal, periprostatic, and pelvic fat in obese men tends to obstruct the visual field and make it more difficult to reach the target organ. These obstacles may explain the higher blood loss and longer operative time seen in severely obese men in our series and are similar to what other studies found $[8,10]$. However, our complication and transfusion rates, hospital stay, margin status, and time to catheter removal were not significantly different in obese versus non-overweight patients.

Our study is currently the largest series to evaluate the impact of obesity on RALP. Limitations of our study include that it is not a randomized prospective analysis, the majority of our patients were Caucasian, and that obesity was a one-time measurement. In addition, since we are primarily a referral center, our population of obese patients may be biased in that only those patients felt to be good surgical candidates by the referring physician are subsequently referred to us. Patients felt to be poor surgical candidates and thus at somewhat higher risk for operative complications may have been referred for other treatment modalities.

\section{Conclusion}

While it has been demonstrated that obese patients can safely undergo minimally invasive surgery, tolerating the anesthetic and Trendelenburg position [22], we now 
demonstrate that obese patients can also be safely considered as candidates for robotic assisted laparoscopic radical prostatectomy with no significant increase in perioperative complications, transfusion rates, or length of hospital stay.

\section{References}

1. Penson DF, Chan JM (2007) Urologic diseases in America project. Prostate Cancer J Urol 177:2020-2029

2. Baskin ML, Ard J, Franklin F, Allison DB (2005) Prevalence of obesity in the United States. Obes Rev 6:5-7

3. Flegal KM, Carroll MD, Ogden CL, Johnson CL (2002) Prevalence and trends in obesity among US adults, 1999-2000. JAMA 288:1723-1727

4. Zorn KC, Gofrit ON, Steinberg GD, Shalhav AL (2007) Evolution of robotic surgery in the treatment of localized prostate cancer. Curr Treat Options Oncol 8(3):197-210

5. Menon M, Tewari A, Peabody J, The VIP Team (2003) Vattikuti Institute prostatectomy: technique. J Urol 169:2289-2292

6. Tewari A, Peabody J, Sarle R et al (2002) Technique of da Vinci robot-assisted anatomic radical prostatectomy. Urology 60:569572

7. Ahlering TE, Eichel L, Edwards R, Skarecky DW (2005) Impact of obesity on clinical outcomes in robotic prostatectomy. Urology 65:740-744

8. Eden CG, Chang CM, Gianduzzo T, Moon DA (2006) The impact of obesity on laparoscopic radical prostatectomy. Br J Urol Int 98:1279-1282

9. Khaira HS, Bruyere F, O'Malley P et al (2006) Does obesity influence the operative course or complications of robot assisted laparoscopic prostatectomy. Br J Urol Int 98:1275-1278

10. Mikhail AA, Stockton BR, Orvieto MA et al (2006) Roboticassisted laparoscopic prostatectomy in overweight and obese patients. J Urol 67:774-779
11. Guillonneau B, Vallancien G (2000) Laparoscopic radical prostatecomy: the Montsouris technique. J Urol 163:1643-1649

12. D'Amico AV, Whittington R, Malco SB et al (1998) Biochemical outcome after radical prostatectomy, external beam radiation therapy, or interstitial radiation therapy for clinically localized prostate cancer. JAMA 280:969-974

13. Chang SS, Duong DT, Wells N et al (2004) Predicting blood loss and transfusion requirements during radical prostatectomy: the significant negative impact of increasing body mass index. J Urol 171:1861-1865

14. El-Feel A, Davis JW, Deger S et al (2003) Laparoscopic radical prostatectomy-an analysis of factors affecting operating time. Urology 62:314-318

15. Bhayani SB, Pavlovich CP, Strup SE et al (2004) Laparoscopic radical prostatectomy: a multi-institutional study of conversion to open surgery. Urology 63:99-102

16. Rodriguez C, Freedland SJ, Deka A et al (2007) Body mass index, weight change, and risk of prostate cancer in the Cancer Prevention Study II Nutrition Cohort. Cancer Epidemiol Biomarkers Prev 16:63-69

17. Wright ME, Chang S-C, Schatzkin A et al (2007) Prospective study of adiposity and weight change in relation to prostate cancer incidence and mortality. Cancer 109:675-684

18. Buschemeyer WC III, Freedland SJ (2007) Obesity and prostate cancer: epidemiology and clinical implications. Eur Urol 52:331343

19. van Roermund JG, Witjes JA (2007) The impact of obesity on prostate cancer. World J Urol 25:491-497

20. Freedland SJ, Grubb KA, Yiu SK et al (2005) Obesity and capsular incision at the time of open retropubic radical prostatectomy. J Urol 174:1798-1801

21. Freedland SJ, Terris MK, Presti JC Jr et al (2004) Obesity and biochemical outcome following radical prostatectomy for organ confined disease with negative surgical margins. J Urol 172:520 524

22. Link RE (2005) Laparoscopic radical prostatectomy in obese patients: feasible or foolhardy? Rev Urol 7(1):53-57 